\title{
A Study of Improving the Competitiveness of Local Undergraduate Colleges
}

\author{
ZHANG Yaqiang ${ }^{\text {a }}$, JING Ruirong ${ }^{\text {b }}$ \\ ${ }^{a}$ School of Management, Hebei University of Technology, Tianjin, China \\ ${ }^{b}$ Department of Business Administration, Xingtai University Xingtai Hebei, China
}

\begin{abstract}
This article discussed strategies innovation and the improvement of competitiveness for local undergraduate colleges by using organizational management and organizational strategy theory. Local colleges should emphasize on the strategic direction of becoming "Qualified Undergraduate Colleges ", be master of advanced experiences as a strategic tool, and continue to optimize the core operating process, so that it can reflect the organizational rules and logic of colleges to calculate the "outside-system" differentiated capabilities, rather than apply the logic of administrative mechanism. At the same time, we use managing environment as "optimal solution" to the strategic innovation of college, positively impact and systematically manage the diversified college industrial environment and bring forward the organizational guarantee mode.
\end{abstract}

Index Terms: Local Undergraduate Colleges; Tending to Margin Strategy; Competitiveness outside the System; Supply Chain; Diversification

(C) 2012 Published by MECS Publisher. Selection and/or peer review under responsibility of the International Conference on E-Business System and Education Technology

\section{Introduction}

Here introduce the paper, and put a nomenclature if necessary, in a box with the same font size as the rest of the paper. The paragraphs continue from here and are only separated by headings, subheadings, images and formulae. The section headings are arranged by numbers, bold and $10 \mathrm{pt}$. Here follows further instructions for authors. At the beginning of the new century, higher education in China has been rapidly pushed into the stage of popular education. The most outstanding performances are the rapidly expansion of enrollment and the number of colleges. In particular, the power of local colleges has been strengthened; especially a number of local colleges also seized the development opportunity to form a new college through mergers and association. Local undergraduate institutions have become a major force in Chinese higher education; in the new industrial environment, location, long-term development mode and the resource-distribution of local colleges have become the central issue of social concern to local institutions even the whole society, including the central government, local government, local communities and the public. 
The new education reform program is no longer emphasize on the industrializing and market-orient of education, but the competition about education resources, students resources, market resources between various colleges at all levels will be much fiercer. Colleges can be essentially seen as education and research functional service organizations providing more public-characterized goods, sometimes the organization management topics of efficiency and effectiveness they face are even more acute and sensitive than regular organization. Management theories of general organizations still have great theoretical value on the issues of college management. In this paper, we draw mature management theory especially strategic management theory to explore the strategic innovation and the enhancement of the competitiveness of local colleges.

\section{Definition and Strategic Direction of Local Colleges}

For the concept of local undergraduate colleges we use, its classification is different from the traditional classification by administrative relationship (for example ministerial or provincial level), and also different from a number of classifications which have a character of planned educational resource distribution (such as key university and general university), but it is closer to "strategic group" classification of competitive strategy theory. This classification emphasizes on the college influences on the development of subjects and the differences in the depth and breadth impacting on the socio-economic development. The impacts of local colleges are limited to the scope of local region, and their influence on the subject is ordinary. Of course, there are still strong connections between various classifications.

Currently, local colleges are mainly provincial or municipal institutions; funding and other resources are mainly from local governments or authorities. They generally locate in middle or small cities. It's difficult for them to configure teachers and students resources of high quality .They lack dominant discipline, have less or even no graduate education, mainly focus on teaching, have a really weak research ability, and just impact the local region or province. With the development of education reform, the development of colleges will gradually dilute the character of traditional classification, and reflect mainly the different impacts to regional social development and different characteristics of subject development. The experiences of foreign institutions show providing good education and research products, gradually expanding or remaining the impact on the disciplines and social development, are the general development way of colleges.

The basic feature of modern organizational strategy theory system which is more explanatory is the "internal and external equilibrium", putting emphasis on the analysis of external environment and the acquisition of internal capabilities at the same time. So the highest level of corporate strategy is innovating future industry or to change the industrial structure, and developing corporate strategy to their advantage .Or we can say the "optimal solution"[1] of strategic management innovation is managing industrial environment, also cultivating strategic anticipation and core operational capabilities as important means[2][3].

Local colleges' strategy should not be confined to the so-called positioning of teaching university, or local universities, and reflect mainly foster the strategic direction of "Qualified Undergraduate Colleges ", gradually breaking their own geographical constraints and improving their discipline status. The core processes construction of teaching and research should be the basis. The framework of strategic analysis can be summed up as "internal and external equilibrium", for one thing is the capacity-building of internal core process; for another is the management of external organization environment.

\section{Construction of Internal Competitiveness of Tending to Margin}

\subsection{Structure Tending to Margin Strategy of university development}

The researches of local college development are agreeable to the opinion that successful development must be correct positioning or take on character. These thoughts reflect that the scholars recognize many factors which affect the development of local colleges, they trying to correct positioning to establish a "difference", in order to avoid falling into the embarrassment of " too choosy to succeed ". But in fact, the classification or 
positioning of college orientation is the result of dynamic development, and does not reflect the nature of college strategy. The so-called well-known colleges generally develop from small and local schools; college development strategy is the strategy which constantly tends to a margin [4].

As for local colleges, Tending to Margin Strategy maintains and challenges a regional and academic influence through the capacity construction of core products and core processes, then constantly advancing themselves to establish a margin influence in a wider range. Tending to Margin Strategy is mainly applicable to standardized products or functional products, rather than creative product [5]. Of course, the final product colleges provided can be seen as creative products, but the "process products"(the teaching process, the research process) which guarantee the final product follow standard rules can be regarded as standard products or functional products, and also can be continuously optimized in accordance with the related standards and logic.

Tending to Margin Strategy is implemented mainly through the continuously optimizing of core teaching and research operational processes. "Competition" between universities is basically the competition on the operating mechanism.

1) Tending to Margin should be defined as a basic competition direction. The main embodiments of the margin direction can be divided into three parts; firstly, it is the direction of the development (evolution) of colleges, tending to the wider scope and greater area influence. Secondly, as a learning goal, in addition to domestic colleges, we should also use similar foreign college's even famous university as a "frame of reference." Thirdly, local colleges should emphasize on developing into "eligible colleges", learning advanced experience of foreign universities comprehensively and gradually improving the quality of education and research products through the standardization of teaching and research process.

2) Continuous learning is very important to Tend-to-margin Strategy, mainly achieving sustained improvement through the contrast of the core processes of teaching and research.

\subsection{Construction of core products and processes}

Implementation of trend-to-margin Strategy in companies emphasizes on value chain analysis, as a special social organization college needs to form a similar strategic value analysis. It is mainly about the study of core product / service and core operational processes.

\section{1) Products of colleges}

Teaching and scientific research is the central social function of university organization, or known as the "core product." The two products are associated in nature, and indispensable. Too much emphasis from some colleges on the so-called teaching positioning, in strategy practice, may cause tendency of ignoring scientific research, and ultimately affect the realization of its teaching function.

College "Product" has some features different from general services products. (1) Product "quality" is difficult to evaluate in real-time, it should gradually overcome undesirable tendencies of judging the education quality by the employment rate and determining the research quality by the number of result.(2) the final product "quality" is guaranteed by the corresponding "process products", the university's core strategic value lies in the " mechanism competitiveness" of teaching process and research process.(3)The evaluation of process product can not be carried out by the "customers" which refers to students (student family) and the public. It should be held by a third party expert (organization). The local institutions in particular need to gradually establish and make full use of technical experts' agencies which mainly carry out professional activities rather than administrative ones. [6]

2)Central processes of colleges

For local colleges, the outstanding problems on instruction of academic process lie in the following two aspects: first, the lack of research processes; second, over-administrative teaching and research process can not reflect the corresponding professionalism.

University organizational structure and business processes have dual characters: academic character related to scholarly activities' law and administrative character related to administrative needs. Academic character 
and administrative character consist the two-dimension of college organizational structure, and reflect different operational logic (effectiveness and efficiency). Their internal contradictions are the questions always faced by college administrators.

Operations of colleges require the separation of academic management and administration to some extent, academic activities and administration activities are two sides of the same issue. They are closely linked, coordinated and inseparable. The conflicts and competition of the two kinds of logics and powers accelerate the pace of continue innovation of operation mode. Core business processes of colleges can be summarized as Fig.1 [7].

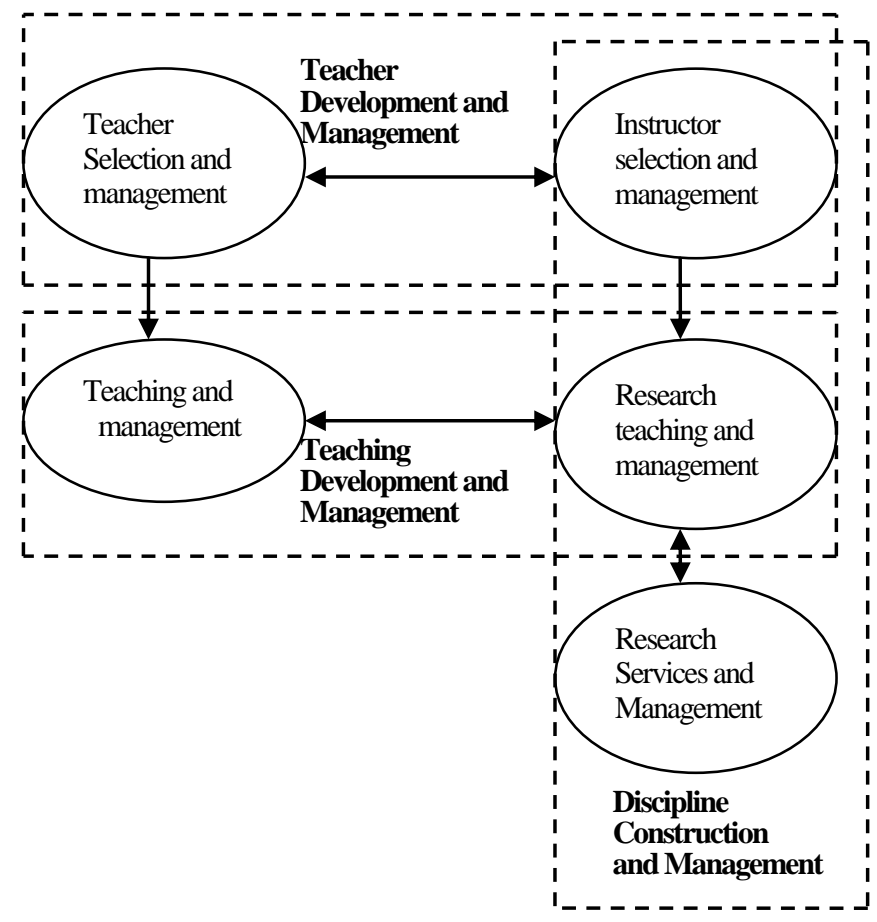

Fig. 1. The core business processes of university

The current higher education implementing the undergraduate teaching evaluation and vertical research reporting and other systems, can be used by strategy of local undergraduate colleges to quickly build a more standardized organizational structure and business processes frame system, in particular the framework of administrative business processes. On this basis, through learning advanced experience of other colleges, local colleges may focus on the characteristics and rules of academic research, and gradually develop their process.

Administrative Macro-regulatory environment will continue to restrict college development, but the strategies of local college are still promising. The standardization of administrative operations can be viewed as a "competitive strength within the system". Making full use of professionals and organizations and gradually casting off the tendency of administrative control in academic operations mean building a kind of "competitive strength outside the system", its capacity of "difference" which is different from others is the source to format school characteristics. 


\section{External Supply Chain Management}

The development of information technology and globalization of market competition, make management science more inclined to dynamic and systematic research, with supply chain theory being one of the typical[8][9]. As a social undertaking organization which provides products and services with an outstanding non-profit character, colleges are facing a more extensive and complex strategic environment or we can call it the "supply chain" environment. Colleges have diverse target markets, such as government, students' families, enterprises, nonprofit organizations, philanthropists, communities, social justices etc, these are all consumers or potential consumers of products and services of education and knowledge. At the same time, they are also diverse "suppliers" of education and research resources; the provision of resources refers to not only financial support, but also the support students, teachers, community environment, the reputation and other resources. In addition, they are the "stakeholders" for social benefits and social responsibility as well.

In the modern diversified world, the target, power, and customers of colleges are all diversified. It's hard to adhere to the development mode which is mainly based on Government support. Different leading forces affecting higher education systems including student-orienting, market-orienting, and government-orienting and so on, need to be embodied in colleges' organizational structure and operation of processes

The management of college supply chain need to develop the extensive relationships with a number of external groups, organizations and also need to strategically organize and coordinate internal departments and functional agency .The extensiveness, complexity and strategic needs of this kind of work should be embodied in organizational machines. For local colleges, it is essential to establish a consultative constitution which provides decision support, information services, coordinate actions, and could help planning policy-making as a whole and coordinating the acquisition and integration of strategic resources, The ideal state is to build the principal's private consultants or secretary institution which is mainly about strategic decision making, avoiding being involved into the formal administrative system and trivial and complex daily administrative work. Given the personnel policy of current system, we can also build such institutions as a consultative and secretary institution subordinate to the principal's administrative meeting or the standing committee of leadership team. As a strategic organization, its administrational character should be minimized.

\section{Conclusion}

The strategy of local colleges needs a wider range of vision and a higher level of aspiration, follow the general trend of the organizational strategic innovation and strategic development of the colleges, and establish the strategic direction of becoming a "qualified college". By means of learning the experiences of similar or well-known institutions home and abroad, local colleges may continuously optimize their teaching and research processes in order to adapt to the operating characteristics and logics of college organizations.

Popularized college education has already exceeded the limit which government's finance can afford. Diversified strategic model of higher education institutions will be inevitable. Local Colleges should be actively adapt to this trend as soon as possible, establish public institutions and development strategy to meet diverse customers' needs, multiple power demands and multi-public-functional locations, at the same time carry out the acquisition and integration of diversified strategic resources.

\section{References}

[1] Altshuller,Innovative Algorithm - TRIZ, System Innovation and Technical Creativity. Technical Innovation Center,Inc., 2003.

[2] Huang Sujian, Huang Qunhui, Modern Enterprise Management - Change View,Beijing: Economics\&Management Press,2007.(in Chinese)

[3] Zhang Dongsheng,Li Yashuang. Strategic Management. Beijing: China Machine Press,2005.(in 
Chinese)

[4] Zhang Dongsheng,Chu Jiandong. Management of Tending to Margin Strategy . Beijing : China Machine Press,2007.(in Chinese)

[5] Ye Guangyu, Lan Hailin. Supply Chain Analysis and Basic Competitive Strategy Options. Nankai Business Review,2002,(1): 33-36.(in Chinese)

[6] Zhang Weiying. Logic of a University. Beijing: Peking University Press,2006.(in Chinese)

[7] Wang Yunfeng. Innovation Research of University Management based on Process analysis. Science of Science and Management of S.\& T.,2004,25(12):85-87.(in Chinese)

[8] Yang Longhua,Lei Ming,The Evolution and Prospects of Study Abroad on Supply Chain Management,Management Scientist,2008,1(1):71-73.(in Chinese)

[9] Ma Shihua,Lin Yong,Supply Chain Management,Beijing: China Machine Press,2007.(in Chinese) 